\title{
DEGRADAÇÃO DE FÁRMACOS RESIDUAIS POR PROCESSOS OXIDATIVOS AVANÇADOS
}

\author{
Silene Alessandra Santos Melo, Alam Gustavo Trovó, Ivonete Rossi Bautitz e Raquel Fernandes Pupo Nogueira* \\ Departamento de Química Analítica, Instituto de Química de Araraquara, Universidade Estadual Paulista, CP 355, 14801-970 \\ Araraquara - SP, Brasil
}

Recebido em 19/12/07; aceito em 17/7/08; publicado na web em 5/12/08

\begin{abstract}
DEGRADATION OF RESIDUAL PHARMACEUTICALS BY ADVANCED OXIDATION PROCESSES. The concern about aquatic ecosystems and the potential risk of drinking water contamination by pharmaceuticals have stimulated the study of processes for the efficient degradation of these contaminants, since the conventional treatment have been inefficient on that purpose. The advanced oxidation processes (AOPs) appear as viable alternatives due to their efficiency on the degradation of different classes of organic contaminants. This review presents an overview of the main AOP $\left(\mathrm{O}_{3}, \mathrm{H}_{2} \mathrm{O}_{2} / \mathrm{UV}, \mathrm{TiO}_{2} / \mathrm{UV}\right.$, Fenton and photo-Fenton $)$ which have been applied to the degradation of different pharmaceuticals. The main results obtained, intermediates identified and toxicity data are presented.
\end{abstract}

Keywords: micropollutants; advanced oxidation processes; sewage treatment plant.

\section{INTRODUÇÃO}

O crescimento demográfico e a expansão industrial trouxeram como consequiência quadros de contaminação atmosférica, do solo e dos recursos hídricos em todo o mundo. Por outro lado, também tem havido uma maior conscientização quanto à deterioração do meio ambiente e à necessidade de se reverter ou ao menos minimizar este processo.

Questões relacionadas à qualidade das águas têm sido extensivamente discutidas, tendo em vista que se trata de um recurso natural imprescindível a um largo espectro de atividades humanas, onde se destacam, entre outros, o abastecimento público e industrial, a irrigação agrícola, a produção de energia elétrica, as atividades de lazer e recreação e a preservação da vida aquática. ${ }^{1}$ Diante dessa conjuntura, temas como reuso, minimização e tratamento de resíduos vêm ganhando cada vez mais importância.

$\mathrm{Na}$ década de 70, começou-se a atentar para a presença de fármacos em ambientes aquáticos. ${ }^{2,3}$ Desde então, diversos estudos têm sido realizados e revelam a presença de resíduos de fármacos em várias partes do mundo.

A principal rota de aporte deste tipo de contaminante em águas superficiais é o lançamento de esgoto in natura, visto que em muitas localidades há um grande déficit de infra-estrutura em saneamento. No Brasil, somente 20,2\% dos municípios coletam e tratam o esgoto doméstico, $32 \%$ só dispõem do serviço de coleta e em $47,8 \%$ dos municípios o esgoto não coletado, é lançado diretamente em águas superficiais. Na região Sudeste a situação é um pouco melhor, mas ainda assim, apenas 33,1\% dos municípios têm serviço de coleta e tratamento do esgoto, $59,8 \%$ somente coletam e em 7,1\% dos municípios não há sequer o serviço de coleta. ${ }^{4}$ Outra rota importante é o lançamento de efluentes de estações de tratamento de esgotos domésticos, uma vez que os fármacos são resistentes aos processos de tratamento utilizados.

Evidentemente, a preocupação a respeito da contaminação e, conseqüentemente, da qualidade da água no Brasil ainda está focada no tratamento de esgotos domésticos que, como relatado anteriormente, ainda é deficitário. No entanto, a contaminação aquática por substâncias constantemente consumidas como fármacos merece especial

\footnotetext{
*e-mail: nogueira@iq.unesp.br
}

atenção, uma vez que os reais riscos à saúde humana e ao ambiente aquático ainda não são totalmente conhecidos.

A preocupação quanto à preservação dos ecossistemas aquáticos e ao risco potencial de contaminação da água de abastecimento público tem incentivado estudos com o objetivo de identificar e quantificar esses resíduos para que se possa minimizar o descarte e desenvolver processos eficientes para removê-los.

Os processos oxidativos avançados (POA) têm sido extensivamente estudados devido ao seu potencial como alternativas ou complementos aos processos convencionais de tratamento de efluentes, uma vez que os radicais hidroxila gerados são altamente reativos e pouco seletivos, podendo atuar na oxidação química de uma vasta gama de substâncias.

O objetivo deste trabalho foi apresentar os principais resultados obtidos na aplicação de diferentes POA à degradação dos fármacos de maior ocorrência em ambientes aquáticos e discutir a formação de intermediários de degradação e sua toxicidade.

\section{RESÍDUOS DE FÁRMACOS NO AMBIENTE}

Os primeiros estudos sobre a presença de fármacos no ambiente datam da década de 70 e foram realizados por Garrison e colaboradores $^{2}$ e Hignite e Azarnoff. ${ }^{3}$ Foi detectada a presença de ácido clofíbrico, metabólito dos antilipêmicos clofibrato e etofibrato, na faixa de concentração de $\mu \mathrm{g} \mathrm{L} \mathrm{L}^{-1}$, em efluentes de estações de tratamento de esgoto (ETE) nos Estados Unidos.

A principal rota de entrada de resíduos de fármacos no ambiente é o lançamento de esgotos domésticos, tratados ou não, em cursos de água. No entanto, também devem ser considerados os efluentes de indústrias farmacêuticas, efluentes rurais, a presença de fármacos no esterco animal utilizado para adubação de solos e a disposição inadequada de fármacos após expiração do prazo de validade..$^{5-7}$

A maior parte dos fármacos que chega às ETE é proveniente de excreção metabólica após prescrição na medicina humana ou veterinária. Os resíduos seguem com o esgoto bruto para as ETE onde são, na maioria dos casos, submetidos a processos convencionais de tratamento. Contudo, os processos convencionais a que são submetidos os esgotos domésticos, baseados na degradação biológica dos contaminantes, não são eficientes para a completa remoção de fármacos residuais por 
possuírem ação biocida ou estruturas químicas complexas não passíveis de biodegradação, comprovado por diversos estudos que mostram a presença desse tipo de contaminante em efluentes de ETE. ${ }^{8-22}$

Fármacos de diversas classes terapêuticas, como antibióticos, hormônios, antilipêmicos, antiinflamatórios, analgésicos, entre outros, têm sido detectados em esgoto doméstico, águas superficiais e subterrâneas em concentrações na faixa de $n g \mathrm{~L}^{-1} \mathrm{a} \mu \mathrm{g} \mathrm{\textrm {L } ^ { - 1 }}$ em várias partes do mundo (Tabela 1).

Tabela 1. Concentrações médias de fármacos detectados em ambientes aquáticos

\begin{tabular}{|c|c|c|c|}
\hline $\begin{array}{l}\text { Fármaco } \\
\text { (classe terapêutica) }\end{array}$ & $\begin{array}{l}\text { Concentração } \\
\text { média }\left(\mu \mathrm{g} \mathrm{L}^{-1}\right)\end{array}$ & Matriz & Ref. \\
\hline $\begin{array}{l}\text { Amoxicilina } \\
\text { (antibiótico) }\end{array}$ & 0,013 & Esgoto bruto/Itália & 8 \\
\hline \multirow{5}{*}{$\begin{array}{l}\text { Atenolol } \\
\text { ( } \beta \text {-bloqueador) }\end{array}$} & 0,49 & Esgoto bruto/Itália & 8 \\
\hline & 0,28 & Efluente de ETE/Itália & 8 \\
\hline & 0,050 & Água superficial/ Itália & 9 \\
\hline & 0,30 & Esgoto bruto/Suécia & 10 \\
\hline & 0,16 & $\begin{array}{l}\text { Efluente de } \\
\text { ETE/Suécia }\end{array}$ & 10 \\
\hline \multirow{8}{*}{$\begin{array}{l}\text { Bezafibrato } \\
\text { (antilipêmico) }\end{array}$} & 0,54 & Efluente de ETE/França & 11 \\
\hline & 0,30 & Efluente de ETE/Itália & 11 \\
\hline & 0,070 & Efluente de ETE/Canadá & 12 \\
\hline & 0,42 & Esgoto bruto/Finlândia & 13 \\
\hline & 1,2 & Esgoto bruto/Brasil & 14 \\
\hline & 0,18 & Água superficial/ Brasil & 14 \\
\hline & 2,2 & Efluente de ETE/Alemanha & 15 \\
\hline & 0,35 & $\begin{array}{l}\text { Água superficial/ } \\
\text { Alemanha }\end{array}$ & 15 \\
\hline \multirow{10}{*}{$\begin{array}{l}\text { Carbamazepina } \\
\text { (anticonvulsionante) }\end{array}$} & 1,7 & Esgoto bruto/Suécia & 10 \\
\hline & 1,2 & Efluente de ETE/Suécia & 10 \\
\hline & 1,0 & Efluente de ETE/França & 11 \\
\hline & 1,0 & Efluente de ETE/Grécia & 11 \\
\hline & 0,38 & Efluente de ETE/Itália & 11 \\
\hline & 0,085 & Efluente de ETE/Canadá & 12 \\
\hline & 2,1 & Efluente de ETE/Alemanha & 15 \\
\hline & 0,25 & $\begin{array}{l}\text { Água superficial/ } \\
\text { Alemanha }\end{array}$ & 15 \\
\hline & 0,50 & Esgoto bruto/Espanha & 16 \\
\hline & 0,48 & Efluente de ETE/Espanha & 16 \\
\hline \multirow{9}{*}{$\begin{array}{l}\text { Cetoprofeno } \\
\text { (antiinflamatório) }\end{array}$} & 0,94 & Esgoto bruto/Suécia & 10 \\
\hline & 0,33 & Efluente de ETE/Suécia & 10 \\
\hline & 0,81 & Efluente de ETE/França & 11 \\
\hline & 2,0 & Esgoto bruto/Finlândia & 13 \\
\hline & 0,15 & Esgoto bruto/Brasil & 14 \\
\hline & 0,22 & Água superficial/ Brasil & 14 \\
\hline & 0,20 & Efluente de ETE/Alemanha & 15 \\
\hline & 1,1 & Esgoto bruto/Espanha & 16 \\
\hline & 0,98 & Efluente de ETE/Espanha & 16 \\
\hline
\end{tabular}

Tabela 1. continuação

\begin{tabular}{|c|c|c|c|}
\hline $\begin{array}{l}\text { Fármaco } \\
\text { (classe terapêutica) }\end{array}$ & $\begin{array}{l}\text { Concentração } \\
\text { média }(\mu \mathrm{g} \mathrm{L}-1)\end{array}$ & Matriz & Ref. \\
\hline \multirow{7}{*}{$\begin{array}{l}\text { Ciprofloxacina } \\
\text { (antibiótico) }\end{array}$} & 0,26 & Esgoto bruto/Itália & 8 \\
\hline & 0,097 & Efluente de ETE/Itália & 8 \\
\hline & 0,060 & Efluente de ETE/França & 11 \\
\hline & 0,070 & Efluente de ETE/Grécia & 11 \\
\hline & 0,030 & Efluente de ETE/Suécia & 11 \\
\hline & 0,37 & Efluente de ETE/Suíça & 17 \\
\hline & 0,020 & Água superficial/EUA & 18 \\
\hline \multirow{13}{*}{$\begin{array}{l}\text { Diclofenaco } \\
\text { (antiinflamatório) }\end{array}$} & 0,16 & Esgoto bruto/Suécia & 10 \\
\hline & 0,12 & Efluente de ETE/Suécia & 10 \\
\hline & 0,33 & Efluente de ETE/França & 11 \\
\hline & 0,84 & Efluente de ETE/Grécia & 11 \\
\hline & 2,47 & Efluente de ETE/Itália & 11 \\
\hline & 0,35 & Esgoto bruto/Finlândia & 13 \\
\hline & 0,40 & Esgoto bruto/Brasil & 14 \\
\hline & 0,020 & Água superficial/Brasil & 14 \\
\hline & 0,81 & Efluente de ETE/Alemanha & 15 \\
\hline & 0,15 & $\begin{array}{l}\text { Água superficial/ } \\
\text { Alemanha }\end{array}$ & 15 \\
\hline & 2,9 & Esgoto bruto/Brasil & 19 \\
\hline & 1,8 & Efluente de ETE/Brasil & 19 \\
\hline & 4,0 & Água superficial/Brasil & 19 \\
\hline \multirow{8}{*}{$\begin{array}{l}17 \alpha \text {-Etinilestradiol } \\
\text { (hormônio contra- } \\
\text { ceptivo) }\end{array}$} & 0,073 & Água superficial/EUA & 18 \\
\hline & 0,001 & Efluente de ETE/Alemanha & 20 \\
\hline & 0,009 & Efluente de ETE/Canadá & 20 \\
\hline & 0,005 & Esgoto bruto/Brasil & 20 \\
\hline & 5,8 & Esgoto bruto/Brasil & 19 \\
\hline & 5,0 & Efluente de ETE/Brasil & 19 \\
\hline & 2,4 & Água superficial/Brasil & 19 \\
\hline & 1,7 & Água potável/Brasil & 19 \\
\hline \multirow{8}{*}{$\begin{array}{l}\text { Genfibrozil } \\
\text { (antilipêmico) }\end{array}$} & 0,71 & Esgoto bruto/Suécia & 10 \\
\hline & 0,18 & Efluente de ETE/Suécia & 10 \\
\hline & 0,70 & Efluente de ETE/França & 11 \\
\hline & 0,71 & Efluente de ETE/Grécia & 11 \\
\hline & 2,14 & Efluente de ETE/Itália & 11 \\
\hline & 0,071 & Efluente de ETE/Canadá & 12 \\
\hline & 0,40 & Esgoto bruto/Brasil & 14 \\
\hline & 0,048 & Água superficial/EUA & 18 \\
\hline \multirow{9}{*}{$\begin{array}{l}\text { Ibuprofeno } \\
\text { (antiinflamatório) }\end{array}$} & 3,6 & Esgoto bruto/Suécia & 10 \\
\hline & 0,15 & Efluente de ETE/Suécia & 10 \\
\hline & 0,92 & Efluente de ETE/França & 11 \\
\hline & 0,050 & Efluente de ETE/Grécia & 11 \\
\hline & 0,070 & Efluente de ETE/Itália & 11 \\
\hline & 0,79 & Efluente de ETE/Canadá & 12 \\
\hline & 13,1 & Esgoto bruto/Finlândia & 13 \\
\hline & 0,60 & Esgoto bruto/Brasil & 14 \\
\hline & 0,19 & Água superficial/Brasil & 14 \\
\hline
\end{tabular}


Tabela 1. continuação

\begin{tabular}{|c|c|c|c|}
\hline $\begin{array}{l}\text { Fármaco } \\
\text { (classe terapêutica) }\end{array}$ & $\begin{array}{l}\text { Concentração } \\
\text { média }\left(\mu \mathrm{g} \mathrm{L}^{-1}\right)\end{array}$ & Matriz & Ref \\
\hline \multirow{7}{*}{$\begin{array}{l}\text { Ibuprofeno } \\
\text { (antiinflamatório) }\end{array}$} & 0,37 & Efluente de ETE/Alemanha & 15 \\
\hline & 0,070 & $\begin{array}{c}\text { Água superficial/ } \\
\text { Alemanha }\end{array}$ & 15 \\
\hline & 0,20 & Água superficial/EUA & 18 \\
\hline & 54,2 & Esgoto bruto/Brasil & 19 \\
\hline & 48,4 & Efluente de ETE/Brasil & 19 \\
\hline & 3,7 & Esgoto bruto/Espanha & 21 \\
\hline & 1,3 & Efluente de ETE/Espanha & 21 \\
\hline \multirow{7}{*}{$\begin{array}{l}\text { Propranolol } \\
\text { ( } \beta \text {-bloqueador) }\end{array}$} & 0,050 & Esgoto bruto/Suécia & 10 \\
\hline & 0,030 & Efluente de ETE/Suécia & 10 \\
\hline & 0,030 & Efluente de ETE/França & 11 \\
\hline & 0,010 & Efluente de ETE/Grécia & 11 \\
\hline & 0,040 & Efluente de ETE/Itália & 11 \\
\hline & 0,17 & Efluente de ETE/Alemanha & 15 \\
\hline & 0,010 & $\begin{array}{c}\text { Água superficial/ } \\
\text { Alemanha }\end{array}$ & 15 \\
\hline \multirow{12}{*}{$\begin{array}{l}\text { Naproxeno } \\
\text { (antiinflamatório) }\end{array}$} & 3,7 & Esgoto bruto/Suécia & 10 \\
\hline & 0,25 & Efluente de ETE/Suécia & 10 \\
\hline & 1,1 & Efluente de ETE/França & 11 \\
\hline & 2,0 & Efluente de ETE/Itália & 11 \\
\hline & 0,27 & Efluente de ETE/Canadá & 12 \\
\hline & 4,9 & Esgoto bruto/Finlândia & 13 \\
\hline & 0,60 & Esgoto bruto/Brasil & 14 \\
\hline & 0,020 & Água superficial/Brasil & 14 \\
\hline & 0,30 & Efluente de ETE/Alemanha & 15 \\
\hline & 0,070 & $\begin{array}{l}\text { Água superficial/ } \\
\text { Alemanha }\end{array}$ & 15 \\
\hline & 4,7 & Esgoto bruto/Espanha & 16 \\
\hline & 1,5 & Efluente de ETE/Espanha & 16 \\
\hline \multirow{10}{*}{$\begin{array}{l}\text { Sulfametoxazol } \\
\text { (antibiótico) }\end{array}$} & 0,080 & Efluente de ETE/França & 11 \\
\hline & 0,090 & Efluente de ETE/Grécia & 11 \\
\hline & 0,010 & Efluente de ETE/Itália & 11 \\
\hline & 0,020 & Efluente de ETE/Suécia & 11 \\
\hline & 0,049 & Efluente de ETE/Canadá & 12 \\
\hline & 0,58 & Esgoto bruto/Espanha & 21 \\
\hline & 0,25 & Efluente de ETE/Espanha & 21 \\
\hline & 0,40 & Efluente de ETE/Alemanha & 22 \\
\hline & 0,41 & $\begin{array}{c}\text { Água subterrânea / } \\
\text { Alemanha }\end{array}$ & 23 \\
\hline & 0,05 & Água superficial/EUA & 24 \\
\hline \multirow{2}{*}{$\begin{array}{l}\text { Tetraciclina } \\
\text { (antibiótico) }\end{array}$} & 0,010 & Água superficial/Itália & 9 \\
\hline & 0,11 & Água superficial/EUA & 18 \\
\hline \multirow{4}{*}{$\begin{array}{l}\text { Trimetoprim } \\
\text { (antibiótico) }\end{array}$} & 0,080 & Esgoto bruto/Suécia & 10 \\
\hline & 0,040 & Efluente de ETE/Suécia & 10 \\
\hline & 0,030 & Efluente de ETE/França & 11 \\
\hline & 0,080 & Efluente de ETE/Grécia & 11 \\
\hline
\end{tabular}

Tabela 1. continuação

\begin{tabular}{lccc}
\hline $\begin{array}{l}\text { Fármaco } \\
\text { (classe terapêutica) }\end{array}$ & $\begin{array}{c}\text { Concentração } \\
\text { média }\left(\mu \mathrm{L} \mathrm{L}^{-1}\right)\end{array}$ & Matriz & Ref. \\
\hline & 0,070 & Efluente de ETE/Itália & 11 \\
Trimetoprim & 0,065 & Efluente de ETE/Canadá & 12 \\
(antibiótico) & 0,15 & Água superficial/EUA & 18 \\
& 0,32 & Efluente de ETE/Alemanha & 22 \\
\hline
\end{tabular}

Estudos demonstram que o nível de concentração dos fármacos encontrados em ambientes aquáticos está relacionado com o padrão de consumo dos mesmos pela população, pela taxa de remoção nas ETE, pelo tipo de efluente que aporta nas ETE e pela sazonalidade..$^{8,13,15}$

\section{DESTINO DOS FÁRMACOS NO AMBIENTE AQUÁTICO}

Os fármacos empregados com um propósito terapêutico, após atuarem no organismo, podem ser excretados como metabólitos, hidrolisados, ou na forma original. Podem ainda estar conjugados com moléculas polares como glicuronídeos, no entanto, esses conjugados são facilmente clivados disponibilizando substâncias farmaceuticamente ativas nos esgotos domésticos..$^{25,26}$

A taxa de excreção da forma inalterada depende do fármaco, da dose e do indivíduo. De modo geral, 40 a $90 \%$ da dose administrada é excretada em sua forma original. ${ }^{9,10,27}$

Uma vez no ambiente, o destino dos fármacos depende de suas características estruturais e propriedades físico-químicas, como fotossensibilidade, biodegradabilidade, lipofilicidade.

Em águas naturais, a presença de substâncias húmicas $(\mathrm{SH})$ e íons nitrato pode contribuir para a degradação de fármacos residuais, uma vez que, sob exposição à irradiação solar, podem gerar espécies altamente reativas como oxigênio singlete $\left({ }^{1} \mathrm{O}_{2}\right)$ e radicais hidroxila (Equações 1 e 2). ${ }^{28-30}$ Por outro lado, as substâncias húmicas absorvem uma extensa faixa da radiação, podendo reduzir a quantidade de energia livre para as outras moléculas orgânicas, funcionando como um filtro e evitando a fotólise direta. ${ }^{28} \mathrm{O}$ efeito total da presença de substâncias húmicas depende do balanço entre suas contribuições opostas, sendo que para cada substância alvo de degradação tal efeito pode ser diferente.

$$
\begin{aligned}
& \mathrm{SH} \stackrel{h v}{\longrightarrow} \mathrm{SH}^{*} \rightarrow{ }^{3} \mathrm{SH}^{*}+\mathrm{O}_{2} \rightarrow \mathrm{SH}+{ }^{1} \mathrm{O}_{2} \\
& \mathrm{NO}_{3}^{-} \stackrel{h v}{\longrightarrow} \mathrm{NO}_{3}^{-*} \rightarrow \mathrm{NO}_{2}^{\cdot}+\mathrm{O}^{\cdot-} \stackrel{\mathrm{H}_{2} \mathrm{O}}{\longrightarrow} \mathrm{NO}_{2}^{*}+\mathrm{HO}^{-}+\mathrm{HO}^{\bullet}
\end{aligned}
$$

Lam e Mabury ${ }^{31}$ estudaram a fotodegradação dos fármacos atorvastatina (antilipêmico), carbamazepina (anticonvulsionante), levofloxacina e sulfametoxazol (antibióticos) e sugeriram que reações de fototransformação constituem um importante fator de limitação da persistência destes fármacos em águas superficiais, seja por fotólise direta, como observado para os antibióticos, ou indireta, pela reação com espécies reativas.

A susceptibilidade à fotodegradação dos antilipêmicos bezafibrato, fenofibrato e genfibrozil foi investigada por Cermola e colaboradores. ${ }^{32}$ Soluções dos fármacos em água destilada foram submetidas à irradiação em um simulador solar e, após 200 h, somente $10 \%$ de degradação foi observada. Na presença de ácidos húmicos e íons nitrato os mesmos resultados foram obtidos para os dois primeiros, no entanto, não se observou degradação de genfibrozil nestas condições. Foi também avaliada a fotólise dos fármacos bezafibrato e genfibrozil quando presentes em efluente de ETE, situação em que não foi observada degradação.

Alguns fármacos, como o ácido acetilsalicílico e a cafeína, são bio- 
degradáveis e, portanto, eficientemente removidos nas ETE, alcançando taxas de remoção de $99,9 \% .{ }^{25,33}$ As penicilinas também são dificilmente encontradas no ambiente, devido à instabilidade química de seu anel $\beta$-lactâmico, que as faz susceptíveis à hidrólise e biodegradação por microorganismos que possuam a enzima $\beta$-lactamase. ${ }^{22}$

Os estrogênios sintéticos e o antibiótico tetraciclina tendem a ser adsorvidos ao lodo das ETE e/ou sedimentos, devido à alta lipofilicidade e formação de precipitado com cálcio e íons similares, respectivamente. ${ }^{7,22,34}$

Existem diversos mecanismos que limitam a persistência dos fármacos em ambientes aquáticos, no entanto, o aporte deste tipo de contaminante é constante, o que confere caráter de pseudopersistência. ${ }^{35}$

É importante salientar que no Brasil há uma maior expectativa de ocorrência de fármacos em águas residuais como conseqüência da carência de tratamento de esgotos no país.

\section{POTENCIAL ECOTOXICOLÓGICO}

Apesar de os fármacos serem detectados no ambiente em baixas concentrações (ng $\left.-\mu \mathrm{g} \mathrm{L}^{-1}\right)$, este quadro gera grande preocupação, uma vez que são substâncias biologicamente ativas que podem desencadear efeitos fármaco-dinâmicos em organismos aquáticos que possuam receptores enzimáticos compatíveis. ${ }^{26,36}$ Assim, a presença de fármacos pode comprometer a qualidade dos recursos hídricos, alterando a biodiversidade e o equilíbrio de ecossistemas aquáticos.

Os estrogênios sintéticos constituem a classe de fármacos mais amplamente discutida na literatura com relação a efeitos adversos em vários organismos. Eles são classificados como desreguladores endócrinos e caracterizam-se por afetar adversamente o desenvolvimento e reprodução de organismos aquáticos. Também estão relacionados ao desenvolvimento de vários tipos de cânceres em humanos. ${ }^{37}$

Cleuvers ${ }^{38}$ realizou bioensaios de toxicidade aguda com Daphnia magna (perda da mobilidade do crustáceo após 48 h), Desmodesmus subscapicatus e Lemna minor (inibição do crescimento da alga após 3 e 7 dias, respectivamente) e determinou a concentração de fármaco que causa efeito negativo mensurável em $50 \%$ da população teste $\left(\mathrm{EC}_{50}\right)$. Para a maioria dos fármacos, os valores de $\mathrm{EC}_{50}$ variaram entre 10 e $100 \mathrm{mg} \mathrm{L}^{-1}$ (toxicidade moderada). O $\beta$-bloqueador propranolol mostrou-se tóxico $\left(1 \mathrm{mg} \mathrm{L}^{-1}<\mathrm{EC}_{50}<10 \mathrm{mg} \mathrm{L}^{-1}\right)$ nos testes realizados com Daphnia magna $\left(\mathrm{EC}_{50}=7,5 \mathrm{mg} \mathrm{L}^{-1}\right)$ e Desmodesmus subscapicatus $\left(\mathrm{EC}_{50}=5,8 \mathrm{mg} \mathrm{L}^{-1}\right)$ e o antiinflamatório diclofenaco mostrou-se tóxico para Lemna minor $\left(\mathrm{EC}_{50}=7,5 \mathrm{mg} \mathrm{L}^{-1}\right)$.

$\mathrm{O}$ antilipêmico genfibrozil e o metabólito ácido clofíbrico mostraram-se altamente tóxicos para bactérias $\left(\mathrm{EC}_{50}<1 \mathrm{mg} \mathrm{L}^{-1}\right)$, no entanto para outras classes taxonômicas os efeitos foram bastante heterogêneos, dependendo da espécie estudada e da idade dos organismos. ${ }^{33}$

Em um estudo de toxicidade frente a algas (inibição do crescimento), o antibiótico amoxicilina mostrou-se altamente tóxico para cianofíceas Synechococcus leopolensis $\left(\mathrm{EC}_{50}=0,002 \mathrm{mg} \mathrm{L}^{-1}\right)$, mas não apresentou toxicidade para clorofiláceas Pseudokirkneriella subcapitata e Closterium ehrenbergii $\left(\mathrm{EC}_{50}>100 \mathrm{mg} \mathrm{L}^{-1}\right){ }^{39}$

Efeitos de toxicidade costumam ser observados somente em concentrações acima de $1 \mu \mathrm{g} \mathrm{L} \mathrm{L}^{-1}$, no entanto, é importante salientar que os bioensaios de toxicidade focam efeitos agudos, quando na realidade os organismos aquáticos são expostos a baixas concentrações de forma contínua e, portanto, efeitos crônicos são mais prováveis. ${ }^{26}$ Estes últimos são mais escassamente avaliados, pois requerem um longo prazo para constatação da toxicidade crônica. Contudo, algumas respostas podem ser associadas a efeitos crônicos como a produção da proteína vitelogenina. Folmar et al ${ }^{40}$ observaram que concentrações a partir de $200 \mathrm{ng} \mathrm{L}^{-1}$ de $17 \beta$-estradiol (estrogênio endógeno) e $100 \mathrm{ng} \mathrm{L}^{-1}$ de $17 \alpha$-etinilestradiol (estrogênio sintético) induziram a síntese da proteína vitelogenina (regulada por estrogênios e, portanto, usualmente encontrada em fêmeas) em peixes machos da espécie Cyprinodon variegatus.

No estudo de Rodgers-Gray et al. ${ }^{41}$ peixes jovens da espécie $R u$ tilus rutilus foram expostos a concentrações gradativas de efluente de ETE por 150 dias contendo além de outros perturbadores endócrinos, estrogênios sintéticos. Os resultados mostraram que a exposição induziu à feminização de peixes machos. Subseqüentemente, os peixes foram gradativamente expostos a águas naturais por mais 150 dias, resultando na redução de vitelogenina no plasma, porém, não se observou alteração no sistema sexual feminizado dos peixes, indicando que o desenvolvimento da anomalia no sistema reprodutivo não foi revertida.

Peixes da espécie Pimephales promelas foram expostos ao $17 \alpha$-etinilestradiol, sendo que concentrações entre 0,1 e $1 \mathrm{ng} \mathrm{L}^{-1}$ provocaram a síntese da proteína vitelogenina após 3 semanas de exposição. ${ }^{42}$ Em outro estudo com essa mesma espécie, este estrogênio sintético na concentração de $4 \mathrm{ng} \mathrm{L}^{-1}$ inibiu o desenvolvimento de tecido testicular após 172 dias de exposição, além de impedir o desenvolvimento de características sexuais secundárias normais. ${ }^{43}$

Não menos importantes são as considerações de que os organismos são expostos a muitos compostos diferentes simultaneamente, podendo ocorrer efeito aditivo ou até mesmo sinérgico entre os fármacos ou outras substâncias presentes no ambiente. ${ }^{36,38}$

\section{TRATAMENTO CONVENCIONAL DE EFLUENTES}

Os processos biológicos são os mais freqüentemente utilizados porque permitem o tratamento de grandes volumes, conseguem alcançar altas taxas de remoção de matéria orgânica e os custos são relativamente baixos. No entanto, alguns compostos são recalcitrantes e podem, inclusive, ser tóxicos aos microrganismos. Em estudos de biodegradação de fármacos as taxas de remoção foram da ordem de $50 \%$ para sistemas convencionais de lodo ativado. ${ }^{44,45}$

Os processos físicos (decantação, flotação, filtração, adsorção) são caracterizados pela transferência de fase do contaminante, sem que este seja de fato degradado. Por outro lado, costumam ser bastante eficientes, podendo ser úteis como pré ou pós-tratamento do processo final. ${ }^{46,47}$ Em ETEs que operam com sistema de lodos ativados a adsorção é o principal mecanismo de remoção de fármacos lipofílicos, como os estrógenos. ${ }^{26,45}$

Os processos químicos baseiam-se na oxidação dos contaminantes pela reação com oxidantes fortes, como peróxido de hidrogênio $\left(\mathrm{H}_{2} \mathrm{O}_{2}\right)$, cloro $\left(\mathrm{Cl}_{2}\right)$, dióxido de cloro $\left(\mathrm{ClO}_{2}\right)$ e permanganato $\left(\mathrm{MnO}_{4}^{-}\right)$. Na maioria dos casos, no entanto, a utilização deste tipo de tratamento não promove a mineralização completa dos contaminantes $\mathrm{CO}_{2}$, havendo a formação de uma grande variedade de sub-produtos de degradação, em geral, ácidos orgânicos (oxálico, tartárico, fórmico, acético). No caso da utilização de $\mathrm{Cl}_{2}$, há a formação de compostos organoclorados, que podem ser mais tóxicos que o contaminante inicial, sendo este o principal inconveniente quanto ao uso deste oxidante. ${ }^{48}$

A eficiência de remoção dos fármacos em ETE depende das propriedades físico-químicas de cada composto. Vários trabalhos relatam que a eliminação destes compostos é freqüentemente incompleta, pois a taxa de remoção é variável. Por exemplo, para o anticonvulsivante carbamazepina uma remoção de $7 \%$ foi observada, enquanto que para o analgésico ácido acetilsalicílico 99\% de remoção foi obtida em uma ETE na Alemanha. ${ }^{15}$ Esta oscilação na taxa de remoção também foi observada em ETE na Finlândia, onde $26 \%$ de remoção foi obtida para diclofenaco e $92 \%$ para ibuprofeno. ${ }^{13}$ Compostos polares tendem a permanecer na fase aquosa, o que favorece sua entrada no ambiente aquático. Por outro lado, compostos pouco polares, são removidos por adsorção no lodo, como mencionado anteriormente. ${ }^{49}$ 
A presença de fármacos em efluentes de ETE é reflexo da baixa eficiência de remoção dos mesmos pelos processos convencionais de tratamento e leva à contaminação de águas superficiais. Tal situação tem incentivado a busca de métodos mais eficientes, capazes de promover a mineralização desses contaminantes, ou pelo menos sua transformação em produtos que não apresentem efeitos adversos ao ambiente.

\section{APLICAÇÃO DOS PROCESSOS OXIDATIVOS AVANÇADOS À DEGRADAÇÃO DE FÁRMACOS RESIDUAIS}

Os POA são caracterizados por reações de oxidação química intermediadas pelo radical hidroxila $\left(\mathrm{HO}^{\circ}\right){ }^{49}$ espécie extremamente reativa e pouco seletiva. $\mathrm{O}$ potencial padrão de redução do radical hidroxila $\left(\mathrm{E}^{0}=2,73 \mathrm{~V}\right)$, muito superior ao dos oxidantes convencionais, faz com que atue na oxidação de uma grande variedade de substâncias.

Os radicais hidroxila são formados a partir de oxidantes como $\mathrm{H}_{2} \mathrm{O}_{2}$ ou $\mathrm{O}_{3}$, sendo que a eficiência pode ser aumentada pela combinação com irradiação ultravioleta (UV) ou visível ou catalisadores (íons metálicos, semicondutores). ${ }^{50}$

Os radicais podem reagir com os contaminantes orgânicos por mecanismos distintos, dependendo da estrutura do composto-alvo. Hidrocarbonetos alifáticos são susceptíveis a reações de abstração de hidrogênio, produzindo radicais orgânicos que rapidamente se ligam ao oxigênio molecular e geram radicais peróxido que, por sua vez, iniciam reações oxidativas em cadeia, levando o substrato orgânico a $\mathrm{CO}_{2}, \mathrm{H}_{2} \mathrm{O}$ e sais inorgânicos (mineralização) (Equações 3 e 4). ${ }^{52,53}$

$\mathrm{RH}+\mathrm{HO}^{\bullet} \rightarrow \mathrm{R}^{\bullet}+\mathrm{H}_{2} \mathrm{O}$

$R^{\bullet}+\mathrm{O}_{2} \rightarrow \mathrm{RO}_{2}^{\bullet} \rightarrow \rightarrow$

Compostos orgânicos que contêm ligações $\pi$ (insaturados e aromáticos) reagem preferencialmente por adição eletrofílica, formando radicais orgânicos (Equação 5).52,53

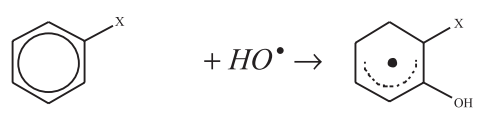

No caso de hidrocarbonetos halogenados ou com alto grau de impedimento estérico, os mecanismos de reação supracitados são desfavorecidos e predomina a transferência eletrônica (Equação 6). ${ }^{52,53}$

$$
\mathrm{RX}+\mathrm{HO}^{\bullet} \rightarrow \mathrm{RX}^{\bullet+}+\mathrm{HO}^{-}
$$

\section{Fotólise de peróxido de hidrogênio}

Sob irradiação UV ocorre a quebra homolítica da molécula de $\mathrm{H}_{2} \mathrm{O}_{2}$, produzindo radicais hidroxila (Equação 7) com rendimento quântico quase unitário $\left(\Phi_{\mathrm{HO}}{ }^{\circ}=0,98\right.$ a $\left.254 \mathrm{~nm}\right) .^{54}$

$$
\mathrm{H}_{2} \mathrm{O}_{2}+h \mathrm{v} \rightarrow 2 \mathrm{HO}^{\bullet}
$$

Geralmente são utilizadas lâmpadas de vapor de mercúrio de média ou baixa pressão, que emitem em comprimento de onda de $254 \mathrm{~nm}$. No entanto, a absortividade do peróxido de hidrogênio é baixa nesta região do espectro $\left(\varepsilon_{254}=18,6 \mathrm{~L} \mathrm{~mol}^{-1} \mathrm{~cm}^{-1}\right)$, sendo necessárias altas concentrações do oxidante para atingir oxidação satisfatória dos contaminantes. Alternativamente, podem ser usadas lâmpadas de mercúrio dopadas com xenônio que emitem na faixa entre 210 e $240 \mathrm{~nm}$, o que implica, no entanto, diretamente no aumento dos custos do processo. ${ }^{54}$
O processo apresenta baixa eficiência no tratamento de efluentes com alta absorbância abaixo de $300 \mathrm{~nm},{ }^{54,55}$ devido à absorção máxima do $\mathrm{H}_{2} \mathrm{O}_{2}$ em $220 \mathrm{~nm}$. Além disso, é dependente do $\mathrm{pH}$, uma vez que em meio alcalino a dissociação do $\mathrm{H}_{2} \mathrm{O}_{2}$ é favorecida formando o íon $\mathrm{HO}_{2}^{-}$, que apresenta maior absortividade molar.

No entanto, a elevação excessiva do $\mathrm{pH}$ prejudica o processo, devido ao seqüestro de radicais hidroxila por íons carbonato e bicarbonato (Equações 8 e 9). A ação competitiva desses íons constitui a principal interferência nos processos oxidativos baseados na produção de radicais $\mathrm{HO}^{\cdot}{ }^{52,54}$

$$
\begin{aligned}
& \mathrm{HO}^{\bullet}+\mathrm{HCO}_{3}^{-} \rightarrow \mathrm{H}_{2} \mathrm{O}+\mathrm{CO}_{3}^{\bullet-} \\
& \mathrm{HO}^{\bullet}+\mathrm{CO}_{3}^{2-} \rightarrow \mathrm{HO}^{-}+\mathrm{CO}_{3}^{\bullet-}
\end{aligned}
$$

Em altas concentrações de peróxido de hidrogênio, podem ocorrer reações que consomem radicais $\mathrm{HO}^{*}$ (Equações 10 a 12), afetando negativamente o processo de degradação. ${ }^{54}$

$$
\begin{aligned}
& \mathrm{H}_{2} \mathrm{O}_{2}+\mathrm{HO}^{\bullet} \rightarrow \mathrm{H}_{2} \mathrm{O}+\mathrm{HO}_{2}^{\bullet} \\
& \mathrm{HO}_{2}^{\bullet}+\mathrm{HO}^{\bullet} \rightarrow \mathrm{H}_{2} \mathrm{O}+\mathrm{O}_{2} \\
& \mathrm{HO}^{\bullet}+\mathrm{HO}^{\bullet} \rightarrow \mathrm{H}_{2} \mathrm{O}_{2}
\end{aligned}
$$

Considerando-se a baixa concentração de fármacos encontrados em águas e efluentes de ETE, a aplicação da fotólise de $\mathrm{H}_{2} \mathrm{O}_{2}$ para sua degradação pode ser efetiva sem a necessidade de utilização de altas concentrações do oxidante. A degradação de fármacos como carbamazepina, ${ }^{56}$ diclofenaco ${ }^{57}$ e paracetamol ${ }^{58}$ foi estudada com concentrações que variaram de 1,51 a $296 \mathrm{mg} \mathrm{L}^{-1}$, atingindo total degradação dos fármacos e remoções de carbono orgânico total (COT) da ordem de $40 \%$ entre 5 e 90 min. A incompleta mineralização dos fármacos é conseqüência da formação de intermediários recalcitrantes, que podem ser mais impactantes que o fármaco original.

\section{Ozonização}

O ozônio pode atuar na oxidação de contaminantes por mecanismo direto ou indireto. No primeiro, a molécula de ozônio reage diretamente por ataque eletrofílico a átomos com uma densidade de carga negativa ou a insaturações. ${ }^{54} \mathrm{O}$ mecanismo indireto envolve a produção de radicais hidroxila em meio alcalino (Equações 13 a 15) ou por irradiação do ozônio (Equações 16 e 17). ${ }^{51,54}$

$\mathrm{O}_{3}+\mathrm{HO}^{-} \rightarrow \mathrm{O}_{2}+\mathrm{HO}_{2}^{-}$

$\mathrm{O}_{3}+\mathrm{HO}_{2}^{-} \rightarrow \mathrm{O}_{3}^{-}+\mathrm{HO}_{2}^{\bullet}$

$\mathrm{O}_{3}+\mathrm{HO}_{2}^{\bullet} \rightarrow 2 \mathrm{O}_{2}+\mathrm{HO}^{\bullet}$

$\mathrm{O}_{3}+\mathrm{H}_{2} \mathrm{O}+h \mathrm{v} \rightarrow \mathrm{H}_{2} \mathrm{O}_{2}+\mathrm{O}_{2}$

$\mathrm{O}_{3}+\mathrm{H}_{2} \mathrm{O}_{2}+h \mathrm{v} \rightarrow \mathrm{HO}^{\bullet}+\mathrm{O}_{2}+\mathrm{HO}_{2}^{\bullet}$

A principal vantagem em se utilizar $\mathrm{O}_{3}$ para gerar radicais hidroxila é que sua absortividade molar é bem maior que a do $\mathrm{H}_{2} \mathrm{O}_{2}\left(\varepsilon_{254}\right.$ $\left.=3300 \mathrm{~L} \mathrm{~mol}^{-1} \mathrm{~cm}^{-1}\right) \mathrm{e}$, portanto, pode ser aplicado ao tratamento de efluentes com alta absorbância. ${ }^{54}$

A ozonização não requer necessariamente o uso de irradiação, uma vez que os radicais $\mathrm{HO}^{*}$ podem ser produzidos pela combinação de $\mathrm{O}_{3}$ e $\mathrm{H}_{2} \mathrm{O}_{2}$. No entanto, perdem-se as contribuições da fotólise do 
$\mathrm{H}_{2} \mathrm{O}_{2}$ e a fotoativação do contaminante orgânico, embora esta última seja irrelevante na maioria dos casos. ${ }^{59}$

Pode-se ainda aplicar a combinação $\mathrm{O}_{3} / \mathrm{H}_{2} \mathrm{O}_{2} / \mathrm{UV}$, o que acelera a produção de radicais hidroxila (Equação 17), aumentando a eficiência do processo..$^{50,54}$

As desvantagens da ozonização estão relacionadas ao custo de produção do $\mathrm{O}_{3}$, a limitações por transferência de massa do $\mathrm{O}_{3}$ gasoso à fase aquosa e à formação de bromatos. ${ }^{54}$

A degradação de amoxicilina, ${ }^{60}$ bezafibrato,${ }^{61}$ diclofenaco,${ }^{62}$ ibuprofeno ${ }^{62,63}$ e paracetamol ${ }^{58}$ em concentrações entre 1,51 a $365 \mathrm{mg}$ $\mathrm{L}^{-1}$ foi estudada empregando o processo de ozonização. A ozonização direta mostrou-se eficiente na oxidação dos fármacos (>90\%), com exceção de ibuprofeno cuja degradação só foi possível pela combinação de $\mathrm{O}_{3}$ com $\mathrm{H}_{2} \mathrm{O}_{2}$, atingindo $90 \%$ de oxidação após 10 min de reação. No entanto, a remoção de COT variou entre 10 e 30\%, evidenciando a formação de intermediários recalcitrantes.

\section{Fotocatálise heterogênea}

A fotocatálise heterogênea baseia-se na oxidação química dos contaminantes mediada por um semicondutor ativado por radiação $\mathrm{UV}^{59}$ Em geral, utiliza-se $\mathrm{TiO}_{2}$, devido à sua alta fotoatividade, estabilidade e baixo custo, quando comparado com os demais semicondutores disponíveis. ${ }^{54,59,64}$

A irradiação do semicondutor promove-o a um estado eletronicamente excitado, no qual um elétron da banda de valência passa para a banda de condução gerando um par elétron-lacuna (Equação 18).

$$
\mathrm{TiO}_{2} \stackrel{h v}{\longrightarrow} \mathrm{TiO}_{2}\left(e^{-}+h^{+}\right)
$$

O caráter oxidante da lacuna da banda de valência gera radicais hidroxila pela oxidação de moléculas de $\mathrm{H}_{2} \mathrm{O}$ adsorvidas na superfície do semicondutor (mecanismo indireto) (Equação 19) e também é capaz de oxidar diretamente moléculas orgânicas via lacuna fotogerada (Equação 20). No entanto, o mecanismo de oxidação indireta dos contaminantes predomina sobre o direto devido à alta concentração de moléculas de água adsorvidas na superfície do semicondutor. ${ }^{52}$

$$
\begin{aligned}
& \mathrm{TiO}_{2}\left(h^{+}\right)+\mathrm{H}_{2} \mathrm{O}_{a d} \rightarrow \mathrm{TiO}_{2}+\mathrm{HO}_{a d}^{\bullet}+\mathrm{H}^{+} \\
& \mathrm{TiO}_{2}\left(h^{+}\right)+\mathrm{RX} \text { ad } \rightarrow \mathrm{TiO}_{2}+\mathrm{RX}_{a d}^{\bullet+}
\end{aligned}
$$

O oxigênio dissolvido funciona como receptor de elétrons na banda de condução gerando radicais superóxido $\left(\mathrm{O}_{2}^{-*}\right)$ que, subseqüentemente, geram $\mathrm{H}_{2} \mathrm{O}_{2}$ (Equações 21 a 23) e impedem a recombinação do par elétron-lacuna (Equação 24). ${ }^{52}$

$$
\begin{aligned}
& \mathrm{TiO}_{2}\left(e^{-}\right)+\mathrm{O}_{2} \rightarrow \mathrm{TiO}_{2}+\mathrm{O}_{2}^{\bullet-} \\
& \mathrm{O}_{2}^{\bullet-}+\mathrm{H}_{2} \mathrm{O} \rightarrow \mathrm{HO}_{2}^{\bullet}+\mathrm{HO}^{-} \\
& 2 \mathrm{HO}_{2}^{\bullet} \rightarrow \mathrm{H}_{2} \mathrm{O}_{2}+\mathrm{O}_{2} \\
& \mathrm{TiO}_{2}\left(e^{-}\right)+\mathrm{TiO}_{2}\left(h^{+}\right) \rightarrow \mathrm{TiO}_{2}+\text { calor }
\end{aligned}
$$

O peróxido de hidrogênio também atua como receptor de elétrons e sua adição ao processo é mais vantajoso que o borbulhamento de oxigênio porque, além de evitar o arraste de compostos voláteis, ainda torna o processo mais eficiente pela geração de radicais hidroxila adicionais (Equação 25). ${ }^{52}$

$\mathrm{TiO}_{2}\left(e^{-}\right)+\mathrm{H}_{2} \mathrm{O}_{2} \rightarrow \mathrm{TiO}_{2}+\mathrm{HO}^{-}+\mathrm{HO}^{\bullet}$
Os semicondutores disponíveis para processos de fotocatálise heterogênea apresentam bandas de absorção no UV próximo (320$400 \mathrm{~nm}$ ) permitindo seu uso em aplicações solares. . $^{54,64}$

Apesar da eficiência na mineralização de inúmeras espécies químicas de relevância ambiental, existem inconvenientes de ordem prática que dificultam o tratamento em larga escala, como dificuldade de penetração da irradiação no meio reacional e separação dos catalisadores que são utilizados na forma de finas suspensões. ${ }^{47}$

Uma alternativa é o uso de sistemas que empregam o catalisador imobilizado, como reportado por Coleman et al.${ }^{65}$ para a degradação do contraceptivo $17 \alpha$-etinilestradiol. A fotocatálise heterogênea mostrou-se eficiente na degradação do mesmo, eliminando totalmente a atividade estrogênica em 50 min de tratamento. Entretanto, a utilização de catalisador em suspensão também apresentou eficiência na degradação dos antibióticos sulfametazina ${ }^{66} \mathrm{e}$ tetraciclina, ${ }^{67}$ os quais foram totalmente degradados após $60 \mathrm{~min}$, utilizando os catalisadores $\mathrm{ZnO}$ e $\mathrm{TiO}_{2}$, respectivamente.

\section{Fenton e foto-Fenton}

No processo Fenton os radicais hidroxila são gerados pela decomposição do $\mathrm{H}_{2} \mathrm{O}_{2}$ na presença de íons $\mathrm{Fe}(\mathrm{II})$ em meio ácido (Equação 26).

$\mathrm{Fe}^{2+}+\mathrm{H}_{2} \mathrm{O}_{2} \rightarrow \mathrm{Fe}^{3+}+\mathrm{HO}^{-}+\mathrm{HO}^{\bullet}$

Em solução aquosa, os íons $\mathrm{Fe}^{3+}$ existem na forma de aquo/hidroxo complexos, cuja proporção depende do pH. A irradiação destes complexos com radiação UV-Vis pode promover um elétron de um orbital centrado no ligante para um orbital centrado no metal, resultando na redução de Fe(III) a Fe(II) e oxidação do ligante (Equação 27). Assim, a combinação do processo Fenton com irradiação, chamado processo foto-Fenton, aumenta a eficiência de oxidação, uma vez que regenera $\mathrm{Fe}$ (II) para a reação com $\mathrm{H}_{2} \mathrm{O}_{2}$, além de produzir radicais hidroxila adicionais..$^{55,68,69}$

$\mathrm{Fe}(\mathrm{OH})^{2+}+h \mathrm{v} \rightarrow \mathrm{Fe}^{2+}+\mathrm{HO}^{\bullet}$

$\mathrm{O}$ pH do meio tem papel muito importante na eficiência dos processos Fenton e foto-Fenton. Valores acima de 3,0 fazem com que $\mathrm{Fe}$ (III) precipite na forma de hidróxido insolúvel, por outro lado, abaixo de 2,5 altas concentrações de $\mathrm{H}^{+}$podem seqüestrar radicais hidroxila (Equação 28), ${ }^{69,70}$ além do predomínio de espécies menos hidroxiladas que apresentam menor absortividade, ${ }^{55}$ sendo a necessidade de controle de $\mathrm{pH}$ a maior limitação destes processos.

$\mathrm{HO}^{\bullet}+\mathrm{H}^{+}+e^{-} \rightarrow \mathrm{H}_{2} \mathrm{O}$

A utilização de complexos policarboxilatos de Fe(III) tem se mostrado bastante interessante, considerando a estabilização do ferro em uma faixa mais ampla de $\mathrm{pH}$. Além disso, a transferência de carga ligante-metal destes complexos estende-se até a região do visível, o que os torna viáveis como fonte de ferro em aplicações que empregam a radiação solar. ${ }^{71}$

O ferrioxalato de potássio apresenta absortividade máxima da ordem de $10^{3}-10^{4} \mathrm{~L} \mathrm{~mol}^{-1} \mathrm{~L}^{-1}$ no intervalo entre 200 e $480 \mathrm{~nm}$, e alto rendimento quântico na formação de íons $\mathrm{Fe}^{2+}$, atingindo 1,24 em 300 $\mathrm{nm}$, enquanto que a irradiação de hidroxo complexos tem rendimento de 0,14 em $313 \mathrm{~nm} .{ }^{54,69,72}$ Além disso, os radicais formados na fotólise do $\mathrm{FeOx}$ (Equações 29 a 31) podem colaborar para a oxidação de substâncias orgânicas.

$\left[\mathrm{Fe}\left(\mathrm{C}_{2} \mathrm{O}_{4}\right)_{3}\right]^{3-}+h \mathrm{v} \rightarrow \mathrm{Fe}^{2+}+2 \mathrm{C}_{2} \mathrm{O}_{4}^{2-}+\mathrm{C}_{2} \mathrm{O}_{4}^{-\bullet}$ 
$\mathrm{C}_{2} \mathrm{O}_{4}^{-\bullet}+\left[\mathrm{Fe}\left(\mathrm{C}_{2} \mathrm{O}_{4}\right)_{3}\right]^{3-} \rightarrow \mathrm{Fe}^{2+}+3 \mathrm{C}_{2} \mathrm{O}_{4}^{2-}+2 \mathrm{CO}_{2}$

$\mathrm{C}_{2} \mathrm{O}_{4}^{-\bullet}+\mathrm{O}_{2} \rightarrow \mathrm{O}_{2}^{-\bullet}+2 \mathrm{CO}_{2}$

O processo foto-Fenton emprega reagentes de baixo custo e não tóxicos ao ambiente nas concentrações empregadas. Pode ser aplicado para o tratamento de efluentes com alta absorbância abaixo de $300 \mathrm{~nm}$ devido à alta absortividade do ferrioxalato de potássio, o que permite melhor aproveitamento da radiação solar e, conseqüentemente, tornase atrativo do ponto de vista econômico.

A degradação dos fármacos amoxicilina, bezafibrato, paracetamol ${ }^{73}$ e tetraciclina ${ }^{74}$ foi estudada em efluente de ETE empregando o processo foto-Fenton sob radiação solar. Observou-se degradação superior a 95\% para todos os fármacos em intervalos de tempo de no máximo $5 \mathrm{~min}$, evidenciando a aplicabilidade do processo à degradação de fármacos nesta matriz, na qual são freqüentemente encontrados.

A utilização de lâmpadas de radiação UV também foi eficiente para a degradação de fármacos, como diclofenaco, ${ }^{75}$ metronidazol ${ }^{76}$ e sulfametoxazol, ${ }^{77}$ demonstrando a versatilidade do processo fotoFenton quanto à utilização de diferentes fontes de radiação.

Além dos trabalhos aqui citados, existem na literatura diversos outros que abordam a degradação de fármacos por POA. A Tabela 2 traz uma compilação de alguns destes trabalhos.

Sob o ponto de vista operacional, os POA podem ser aplicados à degradação de resíduos de fármacos, tanto na saída das ETE quanto em etapas finais do processo de tratamento de água. Em efluentes de ETE, a remoção desses resíduos evitaria a contaminação de águas superficiais por essa fonte e, conseqüentemente, os efeitos em organismos aquáticos seriam minimizados. Por outro lado, a água captada para tratamento em estação de tratamento de água, que pode estar contaminada por resíduos de fármacos provenientes de outras fontes, como esgoto doméstico in natura e efluente rural, após passar pelos processos convencionais de tratamento poderia ser submetida a um POA para a remoção de compostos orgânicos presentes, inclusive os resíduos de fármacos. Dessa forma, esses resíduos não estariam presentes na água potável evitando, assim, possíveis efeitos prejudiciais à saúde humana.

\section{INTERMEDIÁRIOS DE DEGRADAÇÃO DE FÁRMACOS, BIODEGRADABILIDADE E TOXICIDADE APÓS A APLICAÇÃO DE DIFERENTES PROCESSOS OXIDATIVOS AVANÇADOS}

A degradação de fármacos por POA, assim como a fotólise direta (a qual depende da absorbância de cada composto), envolve diferentes etapas e várias reações que resultam em diferentes sub-produtos, que podem apresentar maior ou menor toxicidade comparativamente ao fármaco original. Estes intermediários podem manter ou não a atividade funcional do composto original.

Uma vez que vários intermediários podem ser formados durante o tratamento, é importante identificar uma rota de degradação bem como avaliar a toxicidade e o destino destes no ambiente. Alguns trabalhos relatam o uso da técnica de cromatografia gasosa acoplada à espectrometria de massas (CG-MS) para a identificação de intermediários de degradação. No entanto, dependendo da propriedade de alguns compostos, é necessário fazer a derivatização para facilitar sua volatilização, o que pode ocasionar inexatidão dos resultados. Por outro lado, a técnica de cromatografia líquida acoplada à espectrometria de massas (LC-MS) dispensa derivatização e tem sido muito utilizada para a identificação dos intermediários, uma vez que grande parte dos fármacos são compostos polares contendo grupos funcionais como ácidos carboxílicos, fenóis e aminas. Além disso, a técnica de cromatografia líquida acoplada à espectrometria de massas
Tabela 2. Processos oxidativos avançados aplicados à degradação de fármacos

\begin{tabular}{|c|c|c|}
\hline Fármaco & POA & Ref. \\
\hline \multirow{2}{*}{ Amoxicilina } & $\mathrm{O}_{3}$ & 60 \\
\hline & $\mathrm{Fe}^{3+}, \mathrm{FeOx} / \mathrm{H}_{2} \mathrm{O}_{2} / \mathrm{UV}$, solar & 73 \\
\hline \multirow{4}{*}{ Bezafibrato } & $\mathrm{O}_{3}$ & 61 \\
\hline & $\mathrm{O}_{3}, \mathrm{O}_{3} / \mathrm{H}_{2} \mathrm{O}_{2}$ & 63 \\
\hline & $\mathrm{TiO}_{2} / \mathrm{UV}$ & 78 \\
\hline & $\mathrm{Fe}^{3+}, \mathrm{FeOx} / \mathrm{H}_{2} \mathrm{O}_{2} / \mathrm{UV}$, solar & 73 \\
\hline \multirow{3}{*}{ Carbamazepina } & $\mathrm{O}_{3}, \mathrm{O}_{3} / \mathrm{UV}, \mathrm{H}_{2} \mathrm{O}_{2} / \mathrm{UV}$ & 79 \\
\hline & $\mathrm{O}_{3} / \mathrm{H}_{2} \mathrm{O}_{2}$ & 63 \\
\hline & $\mathrm{H}_{2} \mathrm{O}_{2} / \mathrm{UV}$ & 56 \\
\hline \multirow{2}{*}{ Diazepam } & $\mathrm{O}_{3}, \mathrm{O}_{3} / \mathrm{UV}, \mathrm{H}_{2} \mathrm{O}_{2} / \mathrm{UV}$ & 79 \\
\hline & $\mathrm{O}_{3} / \mathrm{H}_{2} \mathrm{O}_{2}$ & 63 \\
\hline \multirow{7}{*}{ Diclofenaco } & $\mathrm{TiO}_{2} / \mathrm{UV}$ & 80 \\
\hline & $\mathrm{Fe}^{2+} / \mathrm{H}_{2} \mathrm{O}_{2} /$ solar & 81 \\
\hline & $\mathrm{Fe}^{3+} / \mathrm{H}_{2} \mathrm{O}_{2} / \mathrm{UV}$ & 75 \\
\hline & $\mathrm{Fe}^{2+} / \mathrm{H}_{2} \mathrm{O}_{2}$ & 82 \\
\hline & $\mathrm{O}_{3}, \mathrm{O}_{3} / \mathrm{UV}, \mathrm{H}_{2} \mathrm{O}_{2} / \mathrm{UV}$ & 79 \\
\hline & $\mathrm{O}_{3}, \mathrm{O}_{3} / \mathrm{H}_{2} \mathrm{O}_{2}$ & 62 \\
\hline & $\mathrm{H}_{2} \mathrm{O}_{2} / \mathrm{UV}$ & 57 \\
\hline \multirow{2}{*}{ Dipirona } & $\mathrm{Fe}^{2+} / \mathrm{H}_{2} \mathrm{O}_{2} /$ solar & \multirow{2}{*}{83} \\
\hline & $\mathrm{TiO}_{2} /$ solar & \\
\hline \multirow{2}{*}{$17 \alpha$-Etinilestradiol } & $\mathrm{TiO}_{2} / \mathrm{UV}$ & 65 \\
\hline & $\mathrm{O}_{3} / \mathrm{H}_{2} \mathrm{O}_{2}$ & 63 \\
\hline \multirow{2}{*}{ Ibuprofeno } & $\mathrm{O}_{3} / \mathrm{H}_{2} \mathrm{O}_{2}$ & 62,63 \\
\hline & $\mathrm{Fe}^{2+} / \mathrm{H}_{2} \mathrm{O}_{2}$ & 82 \\
\hline \multirow{2}{*}{ Iopromida } & $\mathrm{O}_{3}$ & 84 \\
\hline & $\mathrm{O}_{3} / \mathrm{H}_{2} \mathrm{O}_{2}, \mathrm{O}_{3} / \mathrm{UV}$ & 85 \\
\hline \multirow{3}{*}{ Metronidazol } & $\mathrm{H}_{2} \mathrm{O}_{2} / \mathrm{UV}$ & \\
\hline & $\mathrm{Fe}^{2+} / \mathrm{H}_{2} \mathrm{O}_{2}$ & 76 \\
\hline & $\mathrm{Fe}^{2+} / \mathrm{H}_{2} \mathrm{O}_{2} / \mathrm{UV}$ & \\
\hline \multirow{3}{*}{ Naproxeno } & $\mathrm{O}_{3}$ & 84 \\
\hline & $\mathrm{H}_{2} \mathrm{O}_{2} / \mathrm{UV}$ & 86 \\
\hline & $\mathrm{Fe}^{2+} / \mathrm{H}_{2} \mathrm{O}_{2}$ & 82 \\
\hline \multirow{2}{*}{ Paracetamol } & $\mathrm{O}_{3}, \mathrm{H}_{2} \mathrm{O}_{2} / \mathrm{UV}$ & 58 \\
\hline & $\mathrm{Fe}^{3+}, \mathrm{FeOx} / \mathrm{H}_{2} \mathrm{O}_{2} / \mathrm{UV}$, solar & 73 \\
\hline \multirow{2}{*}{ Ranitidina } & $\mathrm{TiO}_{2} / \mathrm{UV}$ & 87 \\
\hline & $\mathrm{Fe}^{2+} / \mathrm{H}_{2} \mathrm{O}_{2}$ & 89 \\
\hline \multirow{2}{*}{ Sulfametazina } & $\mathrm{TiO}_{2} / \mathrm{UV}$ & \\
\hline & $\mathrm{ZnO} / \mathrm{UV}$ & 66 \\
\hline \multirow{4}{*}{ Sulfametoxazol } & $\mathrm{TiO}_{2} / \mathrm{UV}$ & 89 \\
\hline & $\mathrm{Fe}^{2+} / \mathrm{H}_{2} \mathrm{O}_{2} / \mathrm{UV}$ & 77 \\
\hline & $\mathrm{O}_{3}$ & 85 \\
\hline & $\mathrm{O}_{3} / \mathrm{H}_{2} \mathrm{O}_{2}$ & 63 \\
\hline \multirow{2}{*}{ Tetraciclina } & $\mathrm{TiO}_{2} / \mathrm{UV}$ & 67,87 \\
\hline & $\mathrm{Fe}^{3+}, \mathrm{FeOx} / \mathrm{H}_{2} \mathrm{O}_{2} / \mathrm{UV}$, solar & 74 \\
\hline
\end{tabular}


com analisador de massa/carga TOF (Time of Flight) (LC-MS-TOF) permite determinar com grande exatidão a massa molar dos subprodutos formados, facilitando sua identificação.

Os testes de toxicidade complementam as análises químicas, pois fornecem uma resposta global da amostra, identificando possíveis efeitos sinérgicos e biodisponibilidade dos compostos. Alguns testes de toxicidade baseados na alteração da luminescência da bactéria Vibrio fischeri ou na perda de mobilidade do crustáceo Daphnia magna têm sido utilizados para determinar a toxicidade da solução contendo os intermediários formados após a aplicação de um tratamento. Outro parâmetro que permite avaliar a toxicidade dos intermediários é a biodegradabilidade, que é dada pela razão entre a demanda bioquímica de oxigênio após 5 dias e a demanda química de oxigênio $\left(\mathrm{DBO}_{5} / \mathrm{DQO}\right)$.

A toxicidade e biodegradabilidade dos intermediários de uma solução do antibiótico sulfametoxazol ${ }^{77}\left(200 \mathrm{mg} \mathrm{L}^{-1}\right)$ foram avaliadas após a aplicação do processo foto-Fenton. Foi observado pelos resultados da razão $\mathrm{DBO}_{5} / \mathrm{DQO}$ que ao aumentar a dose de $\mathrm{H}_{2} \mathrm{O}_{2}$ de 50 a $550 \mathrm{mg} \mathrm{L}^{-1}$ durante o tratamento, houve um aumento na biodegradabilidade. Outro dado relevante relatado foi que para a menor dose de $\mathrm{H}_{2} \mathrm{O}_{2}\left(50 \mathrm{mg} \mathrm{L}^{-1}\right)$ utilizada ocorreu um aumento da toxicidade da solução, o que indica que nesta condição foram formados intermediários mais tóxicos que o fármaco original. Entretanto, utilizando as maiores concentrações de $\mathrm{H}_{2} \mathrm{O}_{2}$ isso não foi observado, sugerindo que os intermediários formados podem ser diferentes dependendo das condições experimentais, ou que estes compostos sejam rapidamente degradados. A degradação de sulfametoxazol também foi avaliada por fotocatálise heterogênea ${ }^{89}$ Foi observado que a eficiência de remoção de COT variou em função do $\mathrm{pH}$. O fator apontado como responsável por essa variação foi a diferença nas rotas de degradação, as quais levam à formação de compostos que não contêm o anel benzênico ou anel isoxazol. A razão $\mathrm{DBO}_{5} / \mathrm{DQO}$ demonstrou o aumento da biodegradabilidade da solução de sulfametoxazol após a aplicação da fotocatálise heterogênea, enfatizando assim a aplicabilidade desse tratamento.

Na degradação das sulfonamidas, ${ }^{90}$ sulfadiazina, sulfamerazina, sulfadimetoxina e sulfatiazol, por fotocatálise heterogênea, observouse que todas estas moléculas seguem o mesmo mecanismo de degradação. Foi sugerido que a rota inicial de degradação pode ocorrer tanto pelo ataque do radical hidroxila ao anel aromático com a formação de uma ou duas hidroxisulfonamidas, como pela quebra da ligação S-N e a conseqüente liberação de íons sulfato.

A rota de degradação do estrogênio sintético dietilestilbestrol (DES) foi avaliada na presença do complexo Fe(III)-oxalato sob irradiação. Três principais intermediários foram formados, sendo que um destes foi gerado pela adição de um grupo $\mathrm{OH}$ ao anel aromático. Posteriormente, a degradação seguiu dois diferentes mecanismos de reação, que resultaram na formação do DES-4-semiquinona e do DESo-quinona..$^{91}$ A degradação do estrogênio sintético $17 \alpha$-etinilestradiol por ozonização também gerou semiquinonas como primeiros intermediários, que foram posteriormente oxidadas a ácidos orgânicos e dióxido de carbono. ${ }^{92}$

Durante a degradação do bezafibrato por ozonização ${ }^{61}$ foram detectados produtos gerados pelo ataque do radical hidroxila ao anel aromático. Posteriormente ocorreu a abertura do anel que não contém o átomo de cloro, devido à seletividade do ozônio, gerando sub-produtos como aldeídos e cetonas. Também foi observado que o aumento da biodegrabilidade foi proporcional ao aumento da concentração de ozônio utilizada no tratamento.

A fotocatálise heterogênea e o processo foto-Fenton sob irradiação solar foram aplicados na degradação do intermediário estável 4-metilaminoantipirina formado durante a hidrólise do analgésico dipirona. ${ }^{83}$ Após o tratamento por fotocatálise heterogênea, foram identificados 12 produtos de degradação, formados a partir da hidro- xilação do anel aromático e abertura do anel pirazol. No processo foto-Fenton nenhum intermediário foi detectado e apresentou eficiência 5 vezes maior que a fotocatálise heterogênea.

A aplicação de diferentes processos oxidativos avançados (ozonização, $\mathrm{H}_{2} \mathrm{O}_{2} / \mathrm{UV}$ e $\mathrm{TiO}_{2}$ ) foi feita a uma mistura de vários fármacos (carbamazepina, ácido clofíbrico, diclofenaco, sulfametoxazol, ofloxacina e propranolol $)^{93}$ e após um curto tempo de exposição a estes processos (3-5 min), a solução contendo os metabólitos gerados apresentou menor toxicidade quando comparada à solução inicial.

Em contrapartida, ao avaliar a degradação do antiepilético carbamazepina após a aplicação do processo $\mathrm{H}_{2} \mathrm{O}_{2} / \mathrm{UV}$, foi obtida uma série de acridinas como intermediários. ${ }^{56}$ Acridinas apresentam atividade mutagênica e carcinogênica e a possibilidade de sua geração, mesmo em nível traço, pode inviabilizar a aplicação do processo.

Com base nos resultados apresentados, a otimização dos processos de tratamento é indispensável para garantir a completa mineralização dos compostos-alvo, minimizando assim a formação de intermediários tóxicos.

Nesse contexto faz-se necessário o desenvolvimento de métodos analíticos sensíveis que permitam identificar os intermediários e testes de toxicidade confiáveis para dimensionar o impacto dessas substâncias no ambiente.

\section{CONCLUSÕES}

Fármacos de diferentes classes terapêuticas, utilizados tanto na medicina humana como veterinária, são excretados na sua forma original ou como metabólito. Estes resíduos podem contaminar o ambiente aquático caso não sejam naturalmente biodegradados, fotolisados ou eficientemente removidos nas estações de tratamento de esgoto. O desenvolvimento de técnicas analíticas mais sensíveis tem permitido verificar a ocorrência de fármacos em águas e efluen-

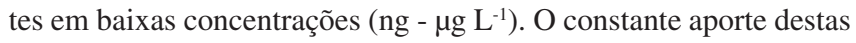
substâncias no ambiente caracterizam-nas como pseudopersistentes, o que pode resultar em graves efeitos ao ambiente aquático e até mesmo à saúde humana.

Diferentes processos oxidativos avançados aplicados à degradação de fármacos de diferentes classes terapêuticas foram descritos neste trabalho. Apesar da complexidade destas moléculas, as baixas concentrações encontradas permitem a utilização destes processos, os quais atingem alta eficiência de degradação como relatado em diversos trabalhos. No entanto, ainda são escassas as informações sobre a identidade dos produtos de degradação formados e a toxicidade da amostra após tratamento, informações estas fundamentais para garantir a efetividade e segurança da aplicação de tais processos no tratamento de efluentes contendo resíduos de fármacos.

\section{AGRADECIMENTOS}

À FAPESP e CAPES pelas bolsas concedidas e ao CNPq pelo apoio financeiro.

\section{REFERÊNCIAS}

1. http://www.cetesb.sp.gov.br/Agua/rios/informacoes.asp, acessada em Abril 2007.

2. Garrison, A. W.; Pope, J. D.; Allen, F. R. Em Identification and Analysis of Organic Pollutants in Water; Keith, C. H., ed.; Ann Arbor Science Publishers: Ann Arbor, 1976, cap. 30.

3. Hignite, C.; Azarnoff, D. L.; Life Sci. 1977, 20, 220.

4. http://www.ibge.gov.br/home/presidencia/noticias/27032002pnsb.shtm, acessada em Abril 2007.

5. Bila, D. M.; Dezotti, M.; Quim. Nova 2003, 26, 523. 
6. Halling-Sorensen, B.; Nielsen, S. N.; Lanzky, P. F.; Ingerslev, F.; HoltenLutzhoft, H. C.; Jorgensen, S. E.; Chemosphere 1998, 36, 357.

7. Heberer, T.; Toxicol. Lett. 2002, 131, 5.

8. Castiglioni, S.; Bagnati, R.; Fanelli, R.; Pomati, F.; Calamari, D.; Zuccato, E.; Environ. Sci. Technol. 2006, 40, 357.

9. Calamari, D.; Zuccato, E.; Castiglioni, S.; Bagnati, R.; Fanelli, R.; Environ. Sci. Technol. 2003, 37, 1241.

10. Bendz, D.; Paxéus, N. A.; Ginn, T. R.; Logr, F. J.; J. Hazard. Mater. 2005, 122, 195.

11. Andreozzi, R.; Marotta, R.; Paxéus, N.; Chemosphere 2003, 50, 1319.

12. Gagné, F.; Blaise, C.; André, C.; Ecotox. Environ. Safety 2006, 64, 329.

13. Lindqvist, N.; Tuhkanen, T.; Kronberg, L.; Water Res. 2005, 39, 2219.

14. Stumpf, M.; Ternes, T. A.; Wilken, R.-D.; Rodrigues, S. V.; Baumann, W.; Sci. Total Environ. 1999, 225, 135.

15. Ternes, T. A.; Water Res. 1998, 32, 3245.

16. Santos, J. L.; Aparicio, I.; Alonso, E.; Callejón, M.; Anal. Chim. Acta $\mathbf{2 0 0 5}, 550,116$.

17. Golet, E. M.; Alder, A. C.; Hartmann, A.; Ternes, T. A.; Giger, W.; Anal. Chem. 2001, 73, 3632.

18. Kolpin, D. W.; Furlong, E. T.; Meyer, M. T.; Thurman, E. M.; Zaugg, S. T.; Barber, L. B.; Buxton, H. T.; Environ. Sci. Technol. 2002, 36, 1202.

19. Ghisele, G.; Tese de Doutorado, Universidade Estadual de Campinas, Brasil, 2006.

20. Ternes, T. A.; Stumpf, M.; Mueller, J.; Haberer, K.; Wilken, R.-D.; Servos, M.; Sci. Total Environ. 1999, 225, 81.

21. Carbala, M.; Omil, F.; Lema, J. M.; Llompart, M.; García-Jares, C.; Rodríguez, I.; Gómez, M.; Ternes, T.; Water Res. 2004, 38, 2918.

22. Hirsch, R.; Ternes, T.; Haberer, K.; Kratz, K.; Sci. Total Environ. 1999, $225,109$.

23. Sacher, F.; Lange, F.; Brauch, H.-J.; Blankenhorn, I.; J. Chromatogr. A 2001, 938, 199.

24. Stackelberg, P. E.; Furlong, E. T.; Meyer, M. T.; Zaugg, S. D.; Henderson, A. K.; Reissman, D. B.; Sci. Total Environ. 2004, 329, 99.

25. Heberer, T.; J. Hydrol. 2002, 266, 175.

26. Fent, K.; Weston, A. A.; Caminada, D.; Aquat. Toxicol. 2006, 76, 122.

27. Mulroy, A.; Wat. Environ. Technol. 2001, 13, 32.

28. Zepp, R. G.; Schlotzhauer, P. F.; Sink, R. M.; Environ. Sci. Technol. 1985, 19, 74.

29. Zepp, R. G.; Hoigné, J.; Bader, H.; Environ. Sci. Technol. 1987, 21, 443.

30. Zhan, M.; Yang, X.; Xian, Q.; Kong, L.; Chemosphere 2006, 63, 378.

31. Lam, M. W.; Mabury, S. A.; Aquat. Sci. 2005, 67, 177.

32. Cermola, M.; Dellagreca, M.; Iesce, M. R.; Previtera, L.; Rubino, M.; Temussi, F.; Brigante, M.; Environ. Chem. Lett. 2005, 3, 43.

33. Richardson, M. L.; Bowron, J. M.; J. Pharm. Pharmacol. 1985, 37, 1.

34. Hernando, M. D.; Mezcua, M.; Fernández-Alba, A. R.; Barceló, D.; Talanta 2006, 69, 334.

35. Daughton, C. G.; Environm. Impact Assessment Rev. 2004, 24, 711.

36. Bound, J. P.; Voulvoulis, N.; Chemosphere 2004, 56, 1143.

37. Reis-Filho, R. W.; Araújo, J. C.; Vieira, E. M.; Quim. Nova 2006, 29, 817.

38. Cleuvers, M.; Toxicol. Lett. 2003, 142, 185.

39. Andreozzi, R.; Caprio, V.; Ciniglia, C.; Champdoré, M.; Giudice, R.; Marotta, R.; Zuccato, E.; Environ. Sci. Technol. 2004, 38, 6832.

40. Folmar, L. C.; Hemmer, M.; Hemmer, R.; Bowman, C.; Kroll, K.; Denslow, N. D.; Aquat. Toxicol. 2000, 49, 77.

41. Rodgers-Gray, T. P.; Jobling, S.; Kelly, C.; Morris, S.; Brighty, G.; Waldock, M. J.; Sumpter, J. P.; Tyler, C. R.; Environ. Sci. Technol. 2001, 35, 462.

42. Pawlowski, S.; van Aerle, R.; Tyler, C.R.; Braunbeck, T.; Ecotoxicol. Environ. Saf. 2004, 57, 330

43. Lange, R.; Hutchinson, T. H.; Croudace, C. P.; Siegmund, F.; Shwein- furth, H.; Hampe, P.; Panter, G. H.; Sumpter, J. P.; Environ. Toxicol. Chem. 2001, 20, 1216

44. Clara, M.; Strenn, B.; Guns, O.; Matinez, E.; Kreuzinger, N.; Kroiss, H.; Water Res. 2005, 39, 4797

45. Radjenovic, J.; Petrovic, M.; Barceló, D.; Anal. Bional. Chem. 2007, 387, 1365.

46. Freire, R. S.; Pelegrini, R.; Kubota, L. T.; Durán, N.; Peralta-Zamora, P.; Quim. Nova 2000, 23, 504.

47. Kunz, A.; Peralta-Zamora, P.; Moraes, S. G.; Durán, N.; Quim. Nova 2002, 25, 78 .

48. Vella, P.A.; Munder, J.A. Em Emerging technologies in hazardous waste management III; Tedder, D. W.; Pohland, F. G., eds.; American Chemical Society: Washington, 1993, cap. 5.

49. Carballa, M.; Omil, F.; Lema, J. M.; Llompart, M.; García-Jares, C.; Rodríguez, I.; Gómez, M.; Ternes, T.; Water Res. 2004, 38, 2918.

50. Glaze, W. H.; Kang, J. W.; Chapin, D. H.; Ozone Sci. Eng. 1987, 9 , 335.

51. Andreozzi, R.; Caprio, V.; Insola, A.; Marotta, R.; Cat. Today 1999, 53, 51.

52. Legrini, O.; Oliveros, E.; Braun, A. M.; Chem. Rev. 1993, 93, 671.

53. Nogueira, R. F. P.; Trovó, A. G.; Silva, M. R. A.; Villa, R. D.; Oliveira, M. C.; Quim. Nova 2007, 30, 400.

54. Domènech, X.; Jardim, W. F.; Litter, M. I. Em Eliminación de contaminantes por fotocatálisis heterogênea; Blesa, M. A., ed.; Digital Grafic: La Plata, 2001, cap. 1.

55. Safarzadeh-Amiri, A.; Bolton, J. R.; Cater, S. R.; J. Adv. Oxid. Technol. 1996, 1,18 .

56. Vogna, D.; Marotta, R.; Andreozzi, R.; Napolitano, A.; D’Ischia, M.; Chemosphere 2004, 54, 497.

57. Vogna, D.; Marotta, R.; Napolitano, A.; Andreozzi, R.; D’Ischia, M.; Water Res. 2004, 38, 414.

58. Andreozzi, R.; Caprio, V.; Marotta, R.; Vogna, D.; Water Res. 2003, 37 , 993.

59. Ollis, D. F. Em Emerging technologies in hazardous waste management III; Tedder, D. W.; Pohland, F. G., eds.; American Chemical Society: Washington, 1993, cap. 2.

60. Andreozzi, R.; Canterino, M.; Marotta, R.; Paxéus, N.; J. Hazard. Mat. 2005, 122, 243

61. Dantas, R. F.; Canterino, M.; Marotta, R.; Sans, C.; Esplugas, S.; Andreozzi, R.; Water Res. 2007, 41, 2525.

62. Zwiener, C.; Frimmel, F. H.; Water Res. 2000, 34, 1881.

63. Huber, M. M.; Canoninca, S.; Park, G-Y,; Von Gunten, U.; Environ. Sci. Technol. 2003, 37, 1016.

64. Gálvez, J. B.; Rodríguez, S. M.; Solar detoxification, Unesco: França, 2001.

65. Coleman, H. M.; Routledge, E. J.; Sumpter, J. P.; Eggins, B. R.; Byrne, J. A.; Water Res. 2004, 38, 3233.

66. Kaniou, S.; Pitarakis, K.; Barlagianni, K.; Poulios, I.; Chemosphere 2005, 60, 372.

67. Reyes, C.; Fernández, J.; Freer, J.; Mondaca, M. A.; Zaror, C.; Malato, S.; Mansilla, H. D.; J. Photochem. Photobiol. A 2006, 184, 141.

68. Zepp, R. G.; Faust, B. C.; Hoigné, J.; Environ. Sci. Technol. 1992, 26, 313.

69. Pignatello, J. J.; Environ. Sci. Technol. 1992, 26, 944.

70. Nogueira, R. F. P.; Guimarães, J. R.; Water Res. 2000, 34, 895.

71. Silva, M. R. A.; Trovó, A. G.; Nogueira, R. F. P.; J. Photochem. Photobiol. A 2007, 191, 187.

72. Safarzadeh-Amiri, A.; Bolton, J. R.; Cater, S. R.; Solar Energy 1996, 56, 439.

73. Trovó, A. G.; Melo, S. A. S.; Nogueira, R. F. P.; J. Photochem. Photobiol. A 2008, 198, 215.

74. Bautitz, I. R.; Nogueira, R. F. P.; J. Photochem. Photobiol. A 2007, 187, 33. 
75. Ravina, M.; Campanella, L.; Kiwi, J.; Water Res. 2002, 36, 3553.

76. Shemer, H.; Kunukcu, Y. K.; Linden, K. G.; Chemosphere 2006, 63, 269.

77. González, O.; Sans, C.; Espulgas, S.; J. Hazard. Mater. 2007, 146, 459.

78. Lambropoulou, D. A.; Konstantinou, I. K.; Thurman, E. M.; Ferrer, I.; Hernando, M. D.; Fernández-Alba, A. R.; Albanis, T. A.; E-Proceedings of $1^{\text {st }}$ European Conference on Environmental Applications of Advanced Oxidation Processes, Chania, Greece, 2006.

79. Gerbhardt, W.; Schröder, H. F.; J. Chromatogr., A 2007, 1160, 34.

80. Calza, P.; Sakkas, V. A.; Medana, C.; Baiocchi, C.; Dimou, A.; Pelizzetti, E.; Albanis, T.; Appl. Catal. B 2006, 67, 197.

81. Pérez-Estrada, L. A.; Malato, S.; Gernjak, W.; Agüera, A.; Thurman, E. M.; Ferrer, I.; Férnandez-Alba, A. R.; Environ. Sci. Technol. 2005, 39 , 8300.

82. Packer, J. L.; Werner, J. J.; Latch, D. E.; McNeill, K.; Arnold, W. A.; Aquat. Sci. 2003, 65, 342.

83. Pérez-Estrada, L. A.; Malato, S.; Agüera, A.; Férnandez-Alba, A. R.; EProceedings of $1^{\text {st }}$ European Conference on Environmental Applications of Advanced Oxidation Processes, Chania, Greece, 2006.
84. Huber, M. M.; Göbel, A.; Joss, A.; Hermann, N.; Löffler, D.; Mcardell, C. S.; Ried, A.; Siegrist, H.; Ternes, T. A.; Gunten, U. V.; Environ. Sci. Technol. 2005, 39, 4290.

85. Ternes, T. A.; Stüber, J.; Herrmann, N.; Mcdowell, D.; Ried, A.; Kampmann, M.; Teiser, B.; Water Res. 2003, 37, 1976.

86. Pereira, V. J.; Weinberg, H. S.; Linden, K. G.; Singer, P. C.; Environ. Sci. Technol. 2007, 41, 1682.

87. Addamo, M.; Augigliaro, V.; Di Paola, A.; García-Lopez, E.; Loddo, V.; Marci, G.; Palmisano, L.; J. Appl. Eletrochem. 2005, 35, 765.

88. Latch, D. E.; Stender, B. L.; Packer, J. L.; Arnold, W. A.; Mcneill, K.; Environ. Sci. Technol. 2003, 37, 3342.

89. Abellán, M. N.; Bayarri, B.; Jiménez, J.; Costa J.; Appl. Catal., B 2007, $74,233$.

90. Calza, P.; Medana, C.; Pazzi, M.; Baiocchi, C.; Pelizzetti, E.; Appl. Catal., B 2004, 53, 63.

91. Zhou, D.; Wu, F.; Deng, N.; Chemosphere 2004, 57, 283.

92. Zhang, X.; Chen, P.; Wu, F.; Deng, N.; Liu, J.; Fang, T.; J. Hazard. Mater. 2006, 133, 291.

93. Andreozzi, R.; Campanella, L; Fríase, B.; Garric, J.; Gonnella, A.; Lo Giudice, R.; Marotta, R.; Pinto, G.; Pollio A.; Water Sci. Technol. 2004, $50,23$. 